
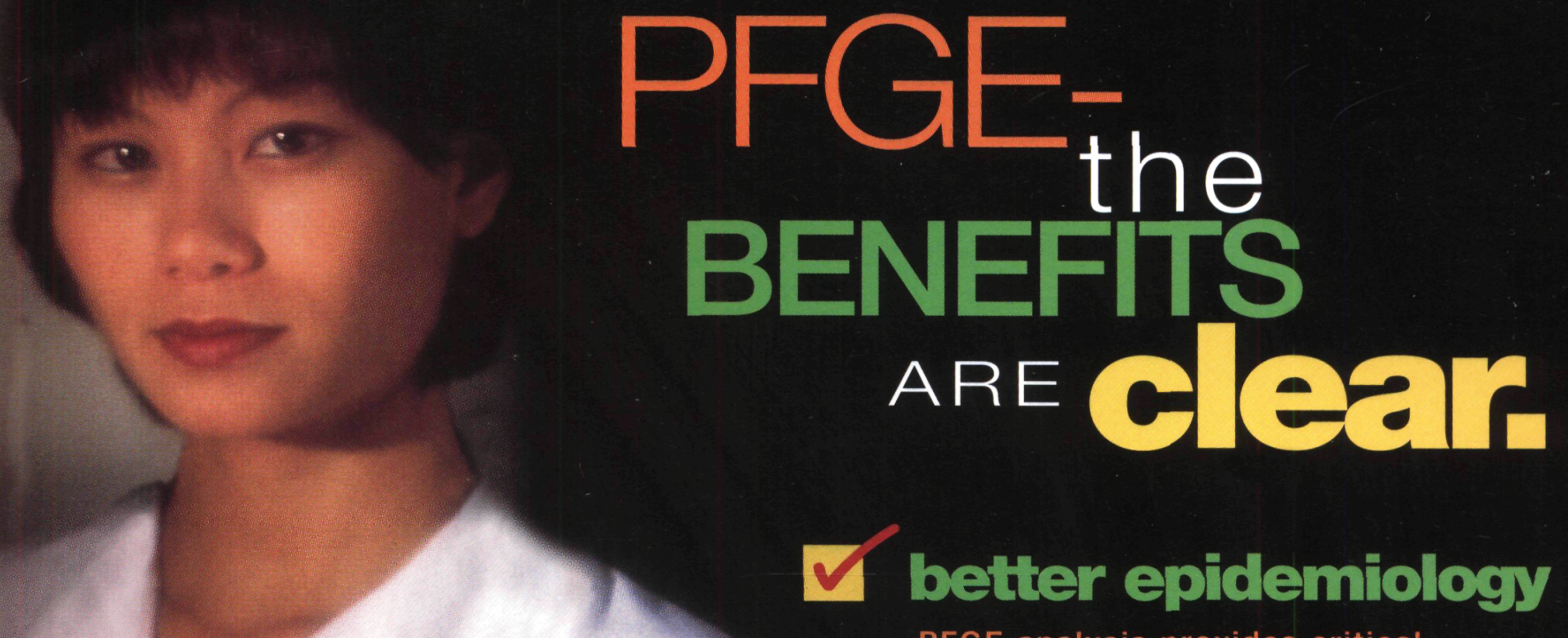

PFGE analysis provides critical

information to surveillance

programs and investigations.

\title{
cost AIEATVE
}

Definitive results mean cost

savings in staff time, antibiotics, and patient isolation.

easy to alopt

The GenePath System includes

preprogrammed instrumentation,

software and complete reagent kits.

Bio-Rad offers expert technical support and extensive user training.

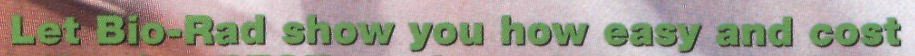

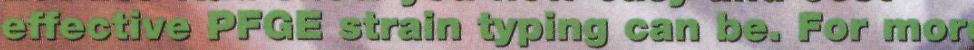
Jufursuajos or to loeato a laboretory

Visit Us at ICAAC' 98 , Booth 1514

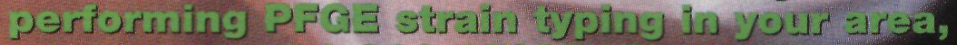

gor tact Us at $1-300-2310$ Find

or PFetinfo@bio-rastsom.

Not FDA approved for in-vitro cliagriostics use.

\section{BIOPAD}

Clinical

Diagnostics Group

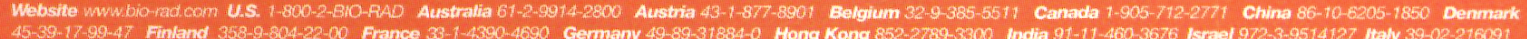

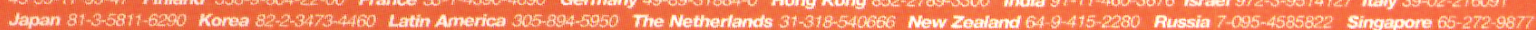
Spain 34-1-667-7085 Swoden 46-3-627-50.00 Switerland 41-1-80955-55 United Kingdom 44-1442-23255? 
A hydrogen peroxide

solution for flexible

\section{endoscope reprocessing}

\section{Completely immersed in}
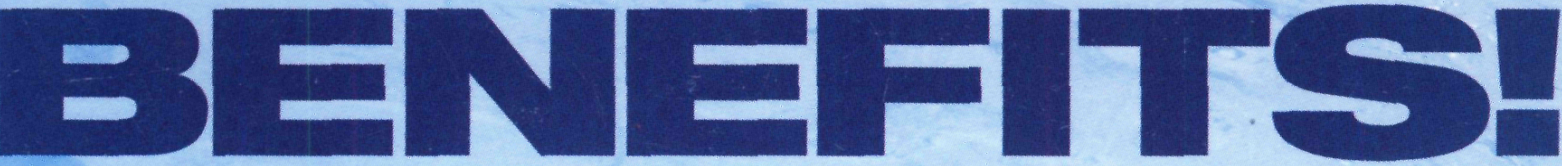

Premixed formula for automatic and manual reprocessing

Fast-acting sporicide, tuberculocide, fungicide, virucide, and bactericide

- High-level disinfection in 30 minutes at room temperature

- Sterilization in 6 hours at room temperature

Does not contain glutaraldehyde

- no aldehyde odor

$\circ$ Cost-effective reusable solution

Compatible with metals, plastics, and elastomers such as those in flexible endoscopes

For more information, call 1-888-4SPOROX.

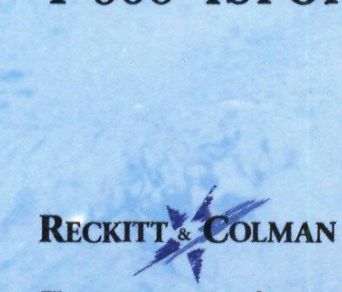

The name to trust for your infection control needs
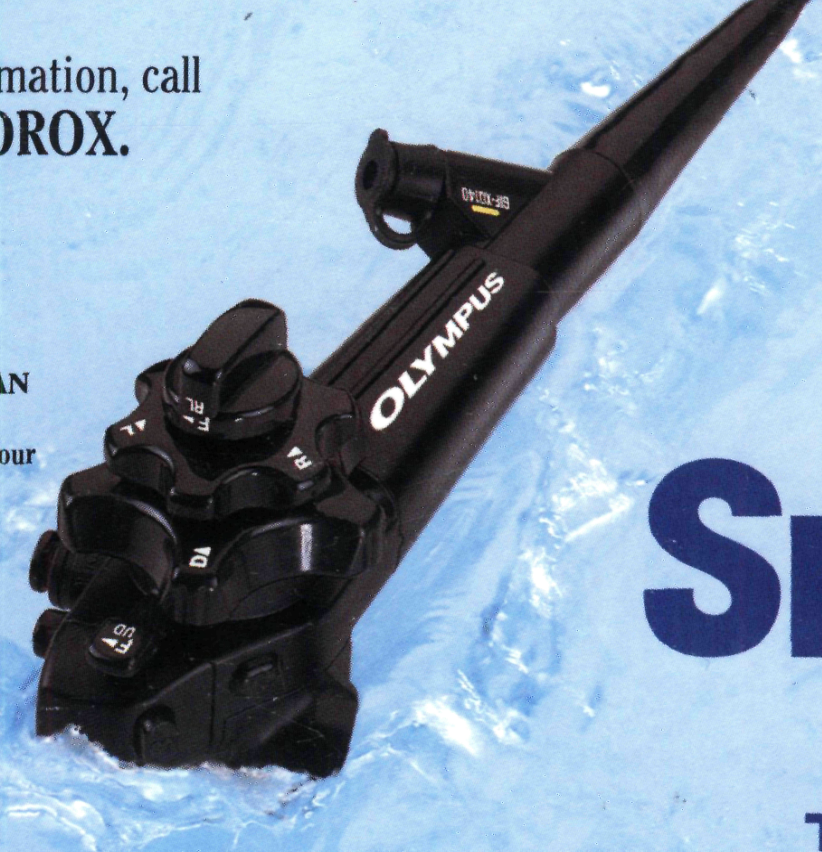